\title{
Effective treatment of steroid and therapy-refractory acute graft- versus-host disease with a novel mesenchymal stromal cell product (MSC-FFM)
}

\author{
Peter Bader ${ }^{1} \cdot$ Zyrafete Kuçi $^{1} \cdot$ Shahrzad Bakhtiar ${ }^{1}$ - Oliver Basu ${ }^{2} \cdot$ Gesine Bug $^{3} \cdot$ Michael Dennis $^{4} \cdot$ Johann Greil $^{5}$. \\ Aniko Barta ${ }^{6} \cdot$ Krisztián M. Kállay $\mathbb{1}^{6} \cdot$ Peter Lang $^{7} \cdot$ Giovanna Lucchini $^{8} \cdot$ Raj Pol $^{9} \cdot$ Ansgar Schulz $^{10}$. \\ Karl-Walter Sykora ${ }^{11} \cdot$ Irene von Luettichau ${ }^{12} \cdot$ Grit Herter-Sprie $^{13} \cdot$ Mohammad Ashab Uddin $^{14} \cdot$ Phil Jenkin $^{14}$. \\ Abdulrahman Alsultan ${ }^{15} \cdot$ Jochen Buechner ${ }^{16}$. Jerry Stein ${ }^{17} \cdot$ Agnes Kelemen $^{18} \cdot$ Andrea Jarisch $^{1} \cdot$ Jan Soerensen $^{1}$. \\ Emilia Salzmann-Manrique ${ }^{1} \cdot$ Martin Hutter $^{1} \cdot$ Richard Schäfer $^{19} \cdot$ Erhard Seifried $^{19} \cdot$ Thomas Klingebiel $^{1}$. \\ Halvard Bonig ${ }^{19} \cdot$ Selim Kuçi ${ }^{1}$
}

Received: 19 December 2017 / Revised: 4 January 2018 / Accepted: 5 January 2018 / Published online: 29 January 2018

(c) The Author(s) 2018. This article is published with open access

\begin{abstract}
The inability to generate mesenchymal stromal cells (MSCs) of consistent potency likely is responsible for inconsistent clinical outcomes of patients with aGvHD receiving MSC products. We developed a novel MSC manufacturing protocol characterized by high in vitro potency and near-identity of individual doses, referred to as "MSC-Frankfurt am Main (MSCFFM)". Herein, we report outcomes of the 69 patients who have received MSC-FFM. These were 51 children and 18 adults with refractory aGvHD grade II (4\%), III (36\%) or IV (59\%). Patients were refractory either to frontline therapy (steroids) (29\%) or to steroids and 1-5 additional lines of immunosuppressants (71\%) were given infusions in four weekly intervals. The day 28 overall response rate was $83 \%$; at the last follow-up, $61 \%$ and $25 \%$ of patients were in complete or partial remission. The median follow-up was 8.1 months. Six-month estimate for cumulative incidence of non-relapse mortality was $27 \%$ (range, 16-38); leukemia relapse mortality was $2 \%$ (range, $0-5$ ). This was associated with a superior six-month overall survival (OS) probability rate of $71 \%$ (range, 61-83), compared to the outcome of patients not treated with MSC-FFM. This novel product was effective in children and adults, suggesting that MSC-FFM represents a promising therapy for steroid refractory aGvHD.
\end{abstract}

\section{Introduction}

Acute graft-versus-host disease (aGvHD) remains a major complication and cause of mortality after allogeneic hematopoietic stem cell transplantation (HSCT). Despite a calcineurin inhibitor-based GvHD prophylaxis without in vivo $\mathrm{T}$ cell depletion, approximately $40 \%$ of patients remain at risk for developing GvHD. The first-line GvHD therapy continues to be corticosteroids, to which about half

Peter Bader, Zyrafete Kuçi, Halvard Bonig, and Selim Kuçi contributed equally to this work.

Peter Bader

peter.bader@kgu.de

Extended author information available on the last page of the article of the patients respond within a few days [1-3]. Despite administration of additional lines and apparently irrespective of the selected therapeutic agent, those patients who are refractory to steroids have very poor outcomes with overall survival (OS) as low as $20 \%$. Third-line treatments include mycophenolate mofetil (MMF), T-cell depleting and anticytokine antibodies and, most recently, Jak inhibitors [4]. Both the aGvHD itself and adverse effects of GvHD treatment, such as hepatic and renal toxicity, opportunistic infections, relapse of the underlying malignant disease and secondary graft failure, contribute to patients' death $[1,2]$. The first promising alternative to immunosuppressants dates back to 2004, when Le Blanc et al. [5]. reported in a landmark paper resolution of a treatment-refractory grade IV aGvHD in a 9-year-old boy by infusion of bone marrowderived mesenchymal stromal cells (MSCs) isolated from the mother. This prompted an initial trial in which eight patients with grade III-IV, biopsy-proven steroid-refractory 
GVHD were infused with MSCs, leading to clinical improvement in six [6]. Based on the encouraging results of these two initial reports, a first phase II trial in 55 adult and pediatric patients with steroid-refractory acute grades II-IV GvHD across 5 European centers was conducted. Bone marrow-derived MSC infusions induced a complete response (CR) in 30 patients and partial response (PR) in 9, with 16 non-responders (NR) to MSC treatment. No side effects related to MSC infusions and no differences in response relative to $\mathrm{MSC}$ donor $\mathrm{MHC}$ matching were reported [7].

The majority of pilot and phase I/II studies confirmed the safety and efficacy of MSC infusions in the aGvHD setting in both pediatric and adult patient populations, although with variable results [8-11]. All clinical studies demonstrated a trend towards a better clinical response in children compared with adults $[12,13]$.

Differences in the results of clinical studies may be due to highly variable quality of MSCs used in the various trials, and more specifically, the lack of a robust manufacturing process which could generate sufficient doses of MSCs with batch-to-batch consistency. We recently reported a novel method for MSC generation from pooled bone marrowderived mononuclear cells of multiple allogeneic donors [14]. A national marketing authorization based on the "hospital exemption" clause of the European advanced therapy medicinal product (ATMP) guidelines was obtained for this MSC product, termed MSC-Frankfurt am Main (MSC-FFM). Herein, we report the outcomes of the first 69 patients with steroid-resistant or treatment-refractory aGvHD treated with MSC-FFM in a routine clinical setting in allogeneic transplant centers across six countries.

\section{Subjects and methods}

\section{Patients and GvHD scoring}

Children and adults with steroid-refractory aGvHD (lack of steroid responsiveness for at least 5 days) or treatmentresistant aGvHD (refractoriness to steroids and at least one additional line of immunosuppressive therapy) after allogeneic HSCT irrespective of HLA matching between patient and donor and GvHD prophylaxis were eligible to receive MSC-FFM. In order to receive MSC, patient and transplant characteristics as well as staging and prior treatment of aGVHD had to be submitted to one of us (PB). Parents or patients gave their informed consent. Primarily, GvHD was diagnosed clinically; histological or other nonclinical evidence was only sought to rule out alternative diagnoses in unclear cases. Acute GvHD scoring was performed using the Seattle-Glucksberg modified criteria [15, 16]. MSC-FFM was dosed at $1-2 \times 10^{6} / \mathrm{kg}$ body weight as a once-weekly rapid intravenous infusion for 1-4 successive weeks. Response was defined as either CR in patients who showed complete resolution of all signs of aGvHD, PR in patients who showed GvHD reduction by at least one grade according to the Glucksberg criteria, or nonresponse (NR) at day 28 after first MSC transfusion. Initially, only 26 children were treated with MSC-FFM as recently reported [14]. Consecutively, more patients (adults and children) with severe steroid and treatment-refractory aGvHD received these MSC products. Herein, we report 69 patients with refractory aGvHD who were treated with MSC-FFM in 14 allogeneic transplant services based in six countries (Germany, Hungary, Israel, Norway, Saudi-Arabia, and UK). Details on the patients' characteristics are presented on Table 1. Of these 69 patients, 26 children were already reported in the initial description of the MSC manufacturing protocol [14].

\section{MSC-FFM}

The development of MSC-FFM manufacturing protocol was previously reported [14]. Donors were selected in accordance with national (German Transfusion Act and ancillary legislation) and international (FACT/JACIE and WMDA) regulation [17]. Pooled mononuclear cells from bone marrow (BM-MNCs) of eight donors were cultured in platelet lysate-supplemented media in order to generate MSCs. Generated MSCs were then frozen in > 200 aliquots (MSC bank) and were further used to generate equipotent clinical-grade MSC-FFM batches in various sizes for patients with different weights.

\section{Statistical analysis}

The response rates (OR, NR) per categories were compared using Fisher's exact test excluding these patients $(N=2)$ from whom no day 28 report was available. We estimated the median survival follow-up time since first MSC infusion using the reverse Kaplan-Meier method.

The OS probability was estimated using Kaplan-Meier statistics. The survival time was considered from the date of the first MSC infusion to the death date or the last follow-up (LFU) date for censored patients. The log-rank test was used to estimate the significance between OS. The nonrelapse mortality (NRM) was defined as death from any cause without previous relapse or progression. Cumulative incidence curves were used to estimate the NRM considering relapse mortality (RM) as a competing risk [18]. Gray's test was used to compare the statistical significance of the difference between the cumulative incidences [19]. The results are expressed as probability or cumulative incidences with its $95 \%$ confidence interval. The six-month predicted estimates for OS and cumulative 
Table 1 Characteristics of patients

\begin{tabular}{|c|c|c|}
\hline & $N=69$ & $100 \%$ \\
\hline \multicolumn{3}{|l|}{ Sex } \\
\hline Female & 21 & $(30 \%)$ \\
\hline Male & 48 & $(70 \%)$ \\
\hline \multicolumn{3}{|l|}{ Age at HSCT } \\
\hline$\leq 18$ y & 51 & $(74 \%)$ \\
\hline Median (range) y & 8.2 & $(0.5-18.0)$ \\
\hline$>18 \mathrm{y}$ & 18 & $(26 \%)$ \\
\hline Median (range) y & 45.5 & $(18.9-65.6)$ \\
\hline \multicolumn{3}{|l|}{ Diagnosis } \\
\hline Malignant & 51 & $(74 \%)$ \\
\hline Non-malignant & 18 & $(26 \%)$ \\
\hline \multicolumn{3}{|l|}{ Donor } \\
\hline MSD & 14 & $(20 \%)$ \\
\hline MUD & 44 & $(64 \%)$ \\
\hline Haploidentical FD & 11 & $(16 \%)$ \\
\hline \multicolumn{3}{|l|}{ Source } \\
\hline $\mathrm{BM}$ & 36 & $(52 \%)$ \\
\hline PBSC & 32 & $(46 \%)$ \\
\hline $\mathrm{CB}$ & 1 & $(1 \%)$ \\
\hline \multicolumn{3}{|l|}{ Conditioning regimen } \\
\hline TBI + others & 15 & $(22 \%)$ \\
\hline BU + others & 15 & $(22 \%)$ \\
\hline TREO + others & 21 & $(30 \%)$ \\
\hline Others & 18 & $(26 \%)$ \\
\hline \multicolumn{3}{|c|}{ In vivo $\mathrm{T}$ cell depletion for conditioning } \\
\hline Without & 17 & $(25 \%)$ \\
\hline ATG & 34 & $(49 \%)$ \\
\hline Campath & 14 & $(20 \%)$ \\
\hline Others & 4 & $(6 \%)$ \\
\hline \multicolumn{3}{|l|}{ GVHD Prophylaxis } \\
\hline Without & 10 & $(14 \%)$ \\
\hline CSA alone & 11 & $(16 \%)$ \\
\hline $\mathrm{CSA}+\mathrm{MTX}$ & 26 & $(38 \%)$ \\
\hline $\mathrm{CSA}+\mathrm{MMF}$ & 7 & $(10 \%)$ \\
\hline Siro + Tacrolimus & 4 & $(6 \%)$ \\
\hline MMF + Tacrolimus & 4 & $(6 \%)$ \\
\hline Others & 7 & $(10 \%)$ \\
\hline
\end{tabular}

Data are $n(\%)$ or median (range) for age

HSCT hematopoietic stem cell transplantation, $y$ years, MSD matched sibling donor, $M U D$ matched unrelated donor ( $>9 / 10$; high resolution match), $F D$ family donor, $B M$ bone marrow, $P B S C$ peripheral blood stem cell, $C B$ cord blood, $T B I$ total body irradiation, $B U$ busulfan, TREO treosulfan, ATG antithymocyte globulin, GVHD graft-versushost disease, CSA cyclosporin A, MTX methotrexate, $M M F$ mycophenolate mofetil

incidences were considered in accordance with other studies [20-22]. All tests were two-tailed, and a $P$-value of $<0.05$ was considered to be statistically significant.
Statistical analyses were performed using the statistical software R, version 3.3.3 (R Project for statistical computing, www.r-project.org/).

\section{Results}

\section{Safety and tolerability}

Sixty-nine patients received a total of 212 doses of MSCFFM. MSC-FFM was administered intravenously immediately after thawing, i.e., while still ice-cold, as a short infusion over no less than $10 \mathrm{~min}$ with clinical and vital parameter monitoring. The maximum volume of product and maximum dose of DMSO were $3-4 \mathrm{ml} / \mathrm{kg}$ and $0.3-0.4 \mathrm{~g} / \mathrm{kg}$, respectively, in the smallest three children weighing between 12-14 $\mathrm{kg}$, and lower than that in all other patients, thus significantly below reported toxic doses of DMSO [23]. Accordingly, there was only one case each of nausea/vomiting, presumably due to DMSO, and headache, both in children, presumably due to the cold infusion solution. No other adverse effects were reported. Thus far, no limiting acute toxicity has been associated with MSC-FFM infusions. Long-term adverse events of particular interest include relapse of the underlying disease or severe infections. Since classical immunosuppressants nonspecifically suppress alloreactivity, adaptive and graft-versusleukemia responses alike, approximately half of the deaths in GvHD patients are due to infection and leukemic relapse which must be considered sequelae of GvHD treatment, as opposed to GvHD itself. With MSC-FFM given on top of immunosuppressive drugs the six month predicted relapse of the underlying mortality rate was only $2 \%(95 \%$ CI $0-5)$ and the total non-relapse mortality only $27 \%$ (16-38) (Table 2). Given the small number of events, overall cohort size, and our inability to distinguish between adverse effects of the classical immunosuppressants and the added effect of MSC-FFM, current data suggest that our cell-based product does not induce long-term adverse effects.

\section{Response and clinical efficacy of MSC-FFM}

At day 28, 22 (32\%) patients achieved CR, 35 (51\%) PR, 10 (14\%) NR and for two of patients (3\%) there were no day 28 data available. This resulted in an overall response (OR) of $83 \%$. At the LFU (median follow-up: 8.19 months; range, 0.9-54.02 months), 42 (61\%) patients were in CR, $17(25 \%)$ patients in PR, and 10 patients (14\%) were NR. These response rates resulted in a predicted six month nonrelapse mortality rate (NRM) of $27 \%$ (95\% CI 16-38) and cumulative leukemia relapse mortality incidence of $2 \%$ (0-5), for an OS rate of 71\% (61-83) (Fig. 1a, b; Table 3).

Patients with aGvHD grade III or grade IV had at 6 month an estimated OS probability of 75\% (59-94) and 
Table 2 Cause of death related to the day 28 response

\begin{tabular}{|c|c|c|c|c|c|c|c|}
\hline & $\begin{array}{l}\text { Severity of aGvHD } \\
\text { prior to MSC-FFM }\end{array}$ & $\begin{array}{l}\text { Treatment prior to } \\
\text { MSC-FFM }\end{array}$ & $\begin{array}{l}\mathrm{CR} \\
(N=22)\end{array}$ & $\begin{array}{l}\mathrm{PR} \\
(N=35)\end{array}$ & $\begin{array}{l}\mathrm{NR} \\
(N=10)\end{array}$ & $\begin{array}{l}\text { No report } \\
(N=2)\end{array}$ & Total \\
\hline \multicolumn{8}{|l|}{ TRM } \\
\hline Aspergillosis/candida & III/IV & $\mathrm{SR} / \mathrm{SR}$ & 2 & & & & 2 \\
\hline Mucor & III/IV & SR/TR, 4 & 1 & 1 & & & 2 \\
\hline Sepsis & III/IV & $\mathrm{SR} / \mathrm{TR}, 3$ & 1 & & 1 & & 2 \\
\hline Virus/Adenovirus & $\mathrm{IV} / \mathrm{IV}$ & $\mathrm{TR}, 5 / \mathrm{TR}, 4$ & & 2 & & & 2 \\
\hline Cerebral haemorrague & IV & TR, 6 & 1 & & & & 1 \\
\hline GvHD & IV/IV/IV/IV & $\begin{array}{l}\text { TR, } 5 / \mathrm{TR}, 3 / \mathrm{TR}, 5 / \\
\mathrm{TR}, 3\end{array}$ & & 2 & 1 & 1 & 4 \\
\hline MOF & III/IV & $\mathrm{TR}, 5 / \mathrm{ST}$ & & & 2 & & 2 \\
\hline $\begin{array}{l}\text { Acute abdomen due to } \\
\text { strangulated hernia }\end{array}$ & III & ST & 1 & & & & 1 \\
\hline No data & IV & $\mathrm{TR}, 5$ & & & 1 & & 1 \\
\hline $\begin{array}{l}\text { Thrombembolism + HSV } \\
\text { pneumonia }\end{array}$ & IV & $\mathrm{TR}, 3$ & & & & 1 & 1 \\
\hline Relapse of the underlying disease & $\mathrm{II} / \mathrm{III} / \mathrm{III}$ & $\mathrm{TR}, 3 / \mathrm{TR}, 4 / \mathrm{TR}, 3$ & & 3 & & & 3 \\
\hline Total & & & $6(27 \%)$ & $8(23 \%)$ & $5(50 \%)$ & $2(100 \%)$ & $21(30 \%)$ \\
\hline
\end{tabular}

Numbers after TR indicates the number of therapy lines used before the treatment with MSC-FFM

$a G v H D$ acute graft-versus-host disease, $C R$ complete response, $P R$ partial response, $N R$ non-response, $T R M$ treatment related mortality, $S R$ steroid refractory, $T R$ treatment refractory, GvHD graft-versus-host disease, MOF multiple organ failure, $H S V$ herpes simplex virus, $M S C$ - $F F M$ Mesenchymal Stromal Cell-Frankfurt am Main

$67 \%$ (54-84), respectively, which seems to be superior to historically expected survival rates for patients with such severe aGvHD (Fig. 2c, d; Table 3).

Clinical responsiveness did not differ between children ( $\leq 18$ years, $n=51$ ) and adults ( $>18$ years, $n=18$ ): Of the 51 children, $13(25 \%)$ and $28(55 \%)$ reached CR or PR by day 28, respectively. Eight (16\%) were NR and in $2(4 \%)$ patients no day 28 report was available. Among those 18 patients $>18$ years of age, $9(50 \%)$ achieved CR, 7 (39\%) PR and $2(11 \%)$ patients did not respond. This resulted in an OR of $80 \%$ in children and $89 \%$ in adults (Table 3). Thus estimated six-month survival rates in children and adults were $75 \%(64-88)$ and $61 \%(42-88)$, respectively $(P=$ $0.398)$. Similarly, non-relapse mortality at six-month was $25 \%(12-36)$ or $33 \%(8-52)$ in children vs. adults, respectively $(P=0.577)$ (Fig. $1 \mathrm{c}, \mathrm{d})$.

\section{Steroid refractory and treatment refractory patients}

The earliest studies used steroid refractoriness for 5-7 days as indication for MSC treatment. We therefore also stratified our patients with respect to whether the patients were refractory to high-dose steroids only vs. therapy-refractory, i.e., having received and failed to respond to additional lines of treatment on top of highdose steroids. Only 20 (29\%) patients belonged to the group of steroid-refractory patients. Of these, $19(95 \%)$ patients responded to MSC-FFM, 13 (65\%) achieved CR, $6(30 \%)$ PR and $1(5 \%)$ patient did not respond by day 28.
At the LFU (median follow-up: 8.19 months; range: 0.9-54.02 months) 16 patients (80\%) had achieved CR and 4 PR $(20 \%)$. The majority of the patients $(N=49$, $71 \%$ ) were treatment-refractory to at least three or more lines of immune suppressive treatment. Of these, 38 (78\%) patients responded, 9 (18\%) with CR, $29(59 \%)$ with PR, and 9 (18\%) showed no response at day 28; in 2 (4\%) patients no day 28 report was available. At the LFU, MSC-FFM treatment resulted in an OR in 39 (80\%), 26 (53\%) achieved CR, $13(27 \%)$ patients PR, and $10(20 \%)$ patients did not respond (Table 2). The outcomes of steroid-refractory vs. treatment-refractory patients did not reveal statistically significant differences. The predicted six-month OS was 69\% (52-93) vs. 72\% (60-86) for steroid-refractory vs. treatment-refractory patients $(P=$ $0.925)$ with a NRM of $31 \%(7-48)$ vs. $26 \%(12-38)(P=$ 0.763) (Fig. 1e, f).

There was also no difference in either six-month OS or in NRM of patients with non-malignant $(N=18)$ compared to patients with malignant disease $(N=51)$ (Fig. 2a, b). Moreover, efficacy of MSC-FFM was not different in the treatment of children ( $\leq 18$ years, $n=51$ ) compared to adult patients ( $>18$ years, $N=18$ ), neither in OS nor NRM (Fig. 1c, d). This effect was observed in most of the patients with severe skin (Fig. 3), or intestinal GvHD (Fig. 4), who showed impressive responses to MSC-FMM. A six-year old patient with ALL developed an aGvHD of the skin at day +14 , which was unresponsive to either steroids, MMF or basiliximab. The patient received MSC-FFM at day +33 
Fig. 1 Overall survival and cumulative incidences with estimates at six months after first MSC-FFM administration. a The overall survival (OS) of all patients treated with MSC-FFM. b The cumulative incidence for all patients as to non-relapse mortality (NRM) and relapse mortality (RM) by the underlying disease is displayed. c, d Overall survival and nonrelapse mortality related to the age and therapy prior to MSCFFM administration (e, f). (Colour figure online) a
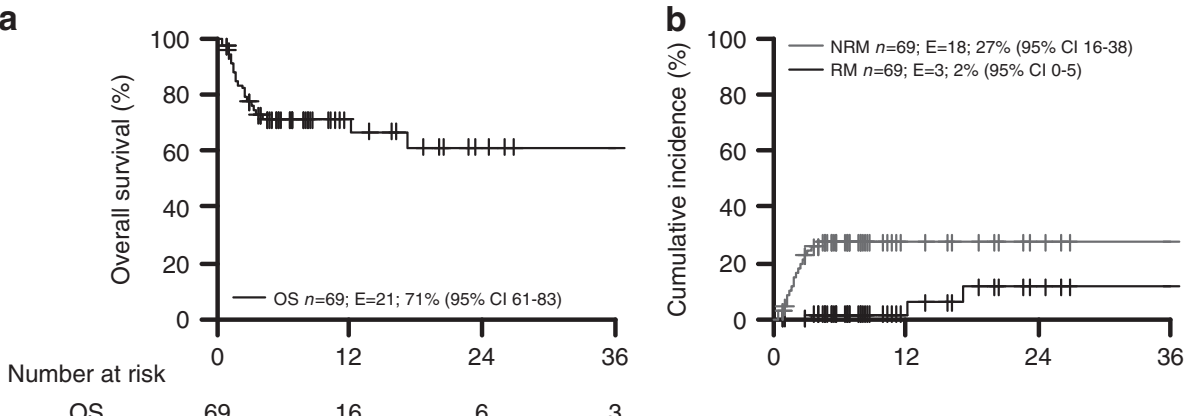

OS

69

16

C

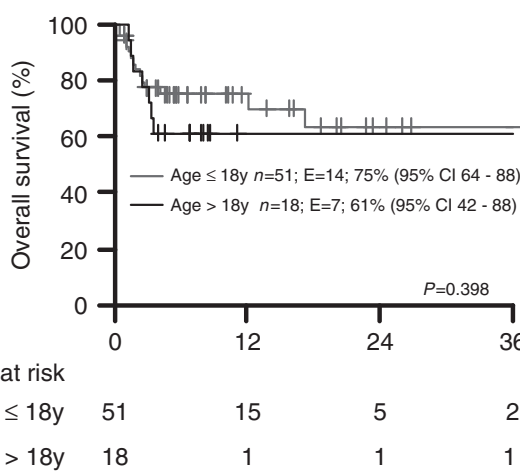

e

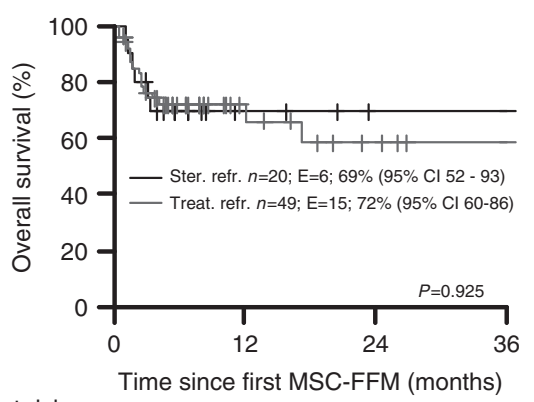

Number at risk

$\begin{array}{ccccc}\text { Ster.-refr. } & 20 & 4 & 1 & 1 \\ \text { Treat.-refr. } & 49 & 12 & 5 & 2\end{array}$

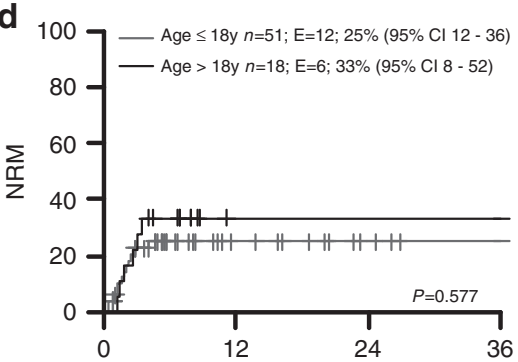

f

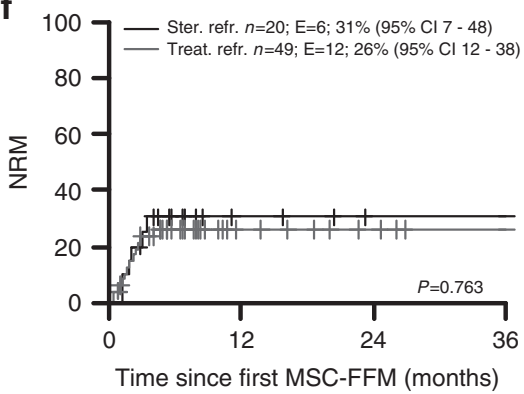

(Fig. 3a, permission to publish picture obtained) and the skin improved substantially 3 days later. Seven days after the first MSC-MMF infusion (Fig. 3b) skin improved continuously (Fig. 3c) and the patient received a second dose. Sixteen days after the first MSC-FFM infusion (day 49), the aGvHD showed a complete response (Fig. 3d).

In addition, MSC-FFM was very effective in the treatment of aGvHD in adult patients. In a 23 year old male patient with AML, GvHD prophylaxis was discontinued because of decreasing donor chimerism on day +115 . Three days later, the patient developed aGvHD grade III (skin stage 2, gut stage 3) (Fig. 4a, b). Acute GvHD proofed to be refractory to steroids and tacrolimus. The patient received altogether 3 doses of MSC-FFM on days $+139,+146$, and +158 . Clinical improvement started already 3 days after the first MSC-FFM application and 14 days thereafter, the colonoscopy showed only mild proctitis (Fig. 4c, d).

\section{Discussion}

Mesenchymal stromal cells are one of the more recent therapeutic modalities considered for aGvHD treatment. Despite the general consensus that MSCs appear to be welltolerated (safe) and effective for the treatment of various diseases, there has been no unambiguous evidence in the field favoring MSC treatment due to inconsistencies in the outcome of GvHD clinical trials [5, 7-9, 14]. Here, we report one of the largest cohorts of patients with refractory aGvHD who, most notably, received the same, standardized MSC-FFM therapy. What distinguishes this report from many of the previous reports is the sheer size of the cohort and its multi-national and multi-hospital routine postapproval setting. With three exceptions, all patients were suffering from grade III $(36 \%)$ or IV $(59 \%)$ GvHD at the time of MSC-FFM therapy. This is a more severely ill 
Table 3 Response status at day 28 after first administration of MSC-FFM and at last follow-up

\begin{tabular}{|c|c|c|c|c|c|c|c|c|c|c|c|c|c|c|c|c|c|c|}
\hline & \multirow[t]{3}{*}{$N$} & \multirow[t]{3}{*}{$(\%)$} & \multicolumn{9}{|c|}{ Day 28} & \multirow[t]{3}{*}{$P$} & \multicolumn{5}{|c|}{ Last follow-up } & \multirow[t]{3}{*}{$P$} \\
\hline & & & \multicolumn{2}{|c|}{ CR } & \multicolumn{2}{|c|}{ PR } & \multicolumn{2}{|c|}{ NR } & \multicolumn{2}{|c|}{$\begin{array}{l}\text { no } \\
\text { report }\end{array}$} & OR & & CR & \multicolumn{2}{|l|}{ PR } & NR & OR & \\
\hline & & & $N$ & $(\%)$ & $N$ & $(\%)$ & $N$ & $(\%)$ & $N$ & $(\%)$ & $N \quad(\%)$ & & $N \quad(\%)$ & $N$ & $(\%)$ & $N \quad(\%)$ & $N \quad(\%)$ & \\
\hline All & 69 & $(100 \%)$ & 22 & $(32 \%)$ & 35 & $(51 \%)$ & 10 & $(14 \%)$ & 2 & $(3 \%)$ & $57(83 \%)$ & & $42(61 \%)$ & 17 & $(25 \%)$ & $10(14 \%)$ & $59(86 \%)$ & \\
\hline Age & & & & & & & & & & & & 0.717 & & & & & & 1 \\
\hline$\leq 18$ y & 51 & $(74 \%)$ & 13 & $(25 \%)$ & 28 & $(55 \%)$ & 8 & $(16 \%)$ & 2 & $(4 \%)$ & $41(80 \%)$ & & $33(65 \%)$ & 10 & $(20 \%)$ & $8 \quad(16 \%)$ & $43(84 \%)$ & \\
\hline$>18 \mathrm{y}$ & 18 & $(26 \%)$ & 9 & $(50 \%)$ & 7 & $(39 \%)$ & 2 & $(11 \%)$ & - & - & $16(89 \%)$ & & $9 \quad(50 \%)$ & 7 & $(39 \%)$ & $2(11 \%)$ & $16(89 \%)$ & \\
\hline Diagnosis & & & & & & & & & & & & 0.706 & & & & & & 0.436 \\
\hline Malignant & 51 & $(74 \%)$ & 17 & $(33 \%)$ & 26 & $(51 \%)$ & 7 & $(14 \%)$ & 1 & $(2 \%)$ & $43(84 \%)$ & & $31(61 \%)$ & 14 & $(27 \%)$ & $6 \quad(12 \%)$ & $45(88 \%)$ & \\
\hline Nonmalignant & 18 & $(26 \%)$ & 5 & $(28 \%)$ & 9 & $(50 \%)$ & 3 & $(17 \%)$ & 1 & $(6 \%)$ & $14(78 \%)$ & & $11(61 \%)$ & 3 & $(17 \%)$ & $4 \quad(22 \%)$ & $14(78 \%)$ & \\
\hline $\begin{array}{l}\text { Severity of } \\
\text { aGVHD prior to } \\
\text { MSC-FFM }\end{array}$ & & & & & & & & & & & & 0.389 & & & & & & 0.472 \\
\hline Grade II & 3 & $(4 \%)$ & 1 & $(33 \%)$ & 2 & $(67 \%)$ & - & - & - & - & $3 \quad(100 \%)$ & & $2 \quad(67 \%)$ & 1 & $(33 \%)$ & -- & $3 \quad(100 \%)$ & \\
\hline Grade III & 25 & $(36 \%)$ & 11 & $(44 \%)$ & 12 & $(48 \%)$ & 2 & $(8 \%)$ & - & - & $23(92 \%)$ & & $15(60 \%)$ & 8 & $(32 \%)$ & $2 \quad(8 \%)$ & $23(92 \%)$ & \\
\hline Grade IV & 41 & $(59 \%)$ & 10 & $(24 \%)$ & 21 & $(51 \%)$ & 8 & $(20 \%)$ & 2 & $(5 \%)$ & $31(76 \%)$ & & $25(61 \%)$ & 8 & $(20 \%)$ & $8 \quad(20 \%)$ & $33(80 \%)$ & \\
\hline $\begin{array}{l}\text { Therapy prior to } \\
\text { MSC-FFM }\end{array}$ & & & & & & & & & & & & 0.655 & & & & & & 0.053 \\
\hline $\begin{array}{l}\text { Steroid- } \\
\text { refractory }\end{array}$ & 20 & $(29 \%)$ & 13 & $(65 \%)$ & 6 & $(30 \%)$ & 1 & $(5 \%)$ & & - & $19(95 \%)$ & & $16(80 \%)$ & 4 & $(20 \%)$ & -- & $20(100 \%)$ & \\
\hline $\begin{array}{l}\text { Treatment- } \\
\text { refractory }\end{array}$ & 49 & $(71 \%)$ & 9 & $(18 \%)$ & 29 & $(59 \%)$ & 9 & $(18 \%)$ & 2 & $(4 \%)$ & $38(78 \%)$ & & $26(53 \%)$ & & $(27 \%)$ & $10(20 \%)$ & $39(80 \%)$ & \\
\hline
\end{tabular}

Data are $n(\%)$. Table shows the reported response status. Comparison between response status (OR, NR) per patient characteristic was performed using Fisher's exact test

$M S C$-FFM Mesenchymal Stromal Cell-Frankfurt am Main, $C R$ complete response, $P R$ partial response, $N R$ non-response, $O R$ overall response, $y$ years, $a G V H D$ acute graft-versus-host disease

cohort than in most published series, as well as it is the most heavily pre-treated one, since only $29 \%$ of the patients were steroid-refractory, while the remainder had received as many as six additional lines of treatment before the decision was made to treat them with MSC-FFM. Of significant interest for the definition of outcome measures for future aGvHD trials, while many of the PR improved to CR over the course of the observation period, very few of the day 28 non-responders had delayed responses, most remained nonresponders throughout.

This observation indicates the predictive value of day 28 responses for overall therapeutic benefit and suggests its use as a surrogate outcome parameter, in agreement with published work [24]. Accordingly, in this study we also used day 28 response as an outcome parameter. In our cohort, 57 of 69 patients $(83 \%)$ responded to the MSC treatment by day $28(\mathrm{OR})$, which is much more encouraging than the results from a randomized placebo-controlled Prochymal aGvHD study. Extraction of data from the Prochymal 280 study from the Australian regulatory agency indicates that the trial enrolled 173 aGvHD patients with steroid refractoriness, 28 of which children; with only $73 \%$ grade $\mathrm{C}$ and grade D. Considering, therefore, only the response data for the 126 patients with severe GvHD, a response rate of $30.2 \%$ was reported. OS at six months for the entire MSC-treated cohort was $34 \%$, compared to $42 \%$ for the placebo group. Thus, this does not provide convincing evidence to support efficacy of Prochymal in adults with aGvHD, while benefit in children was suggested by subgroup analyses within the 280 trial and supported by the 275 trial. Although the primary end point in that study was not achieved for the whole group of patients, there was a significant benefit over placebo group if the liver and GI tract were affected [25].

Le Blanc et al. reported similar response rates to the MSC-treatment of 25 children and 30 adults with acute GvHD compared to the Prochymal data in a multicenter phase II study [7]. The OR for their cohort of patients was $70.5 \%$ at median time from 18 days (3-63 days) and not at day 28 as an outcome end point used in the current study. Response rate in our cohort of patients is also superior to that reported by Introna et al. [26] in a cohort of 15 pediatric patients; that study demonstrated an OR of $66.7 \%$ compared to our pediatric cohort $(80 \%)$. However, in their patient 

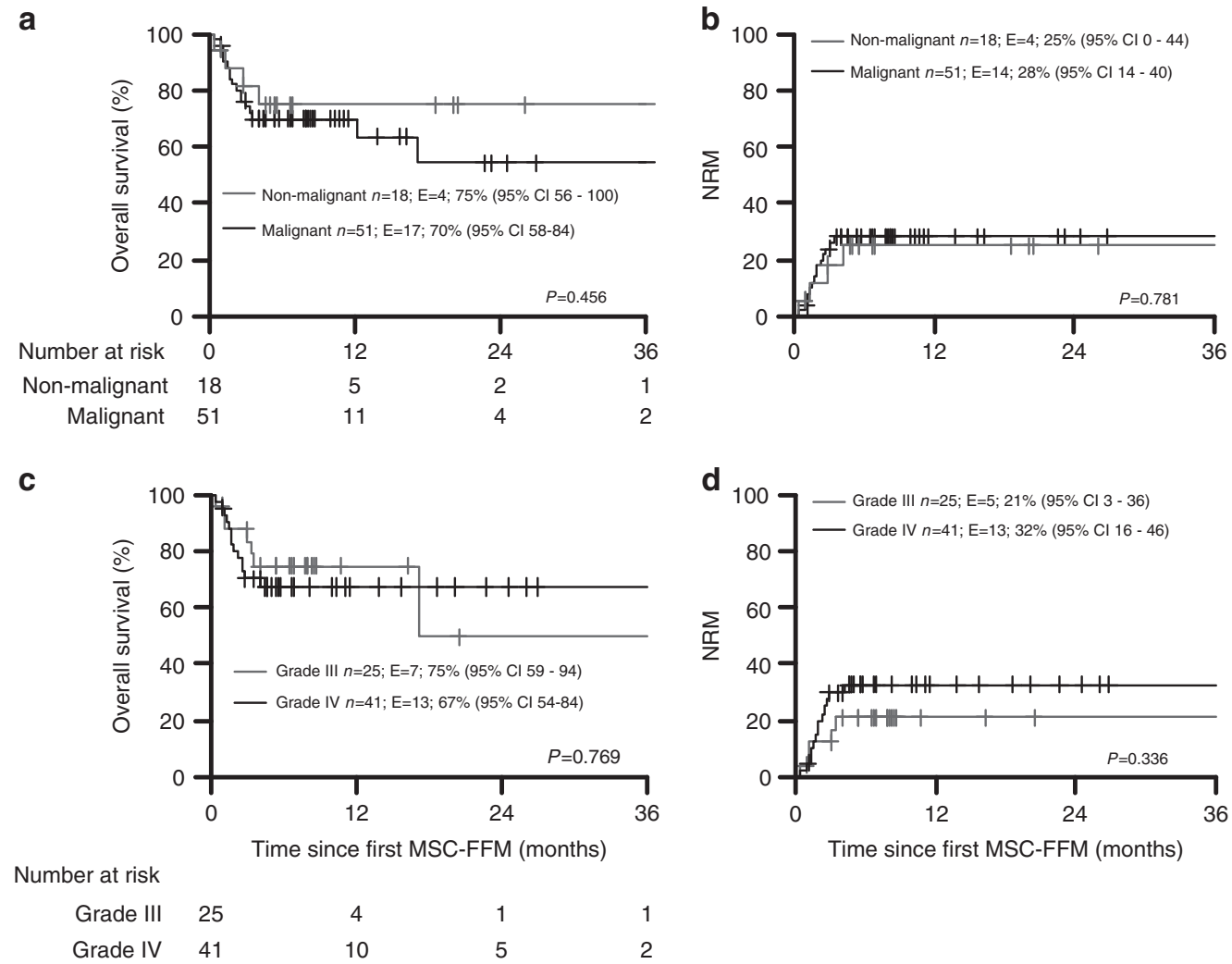

Fig. 2 Overall survival and cumulative incidences with probabilities and estimates at 6-months after first MSC-FFM administration according to disease $(\mathbf{a}, \mathbf{b})$, and (c, d) severity of aGvHD prior

treatment with MSC-MMF. In this panel patients with aGvHD grade II $(n=3,4 \%)$ are not shown. (Colour figure online)

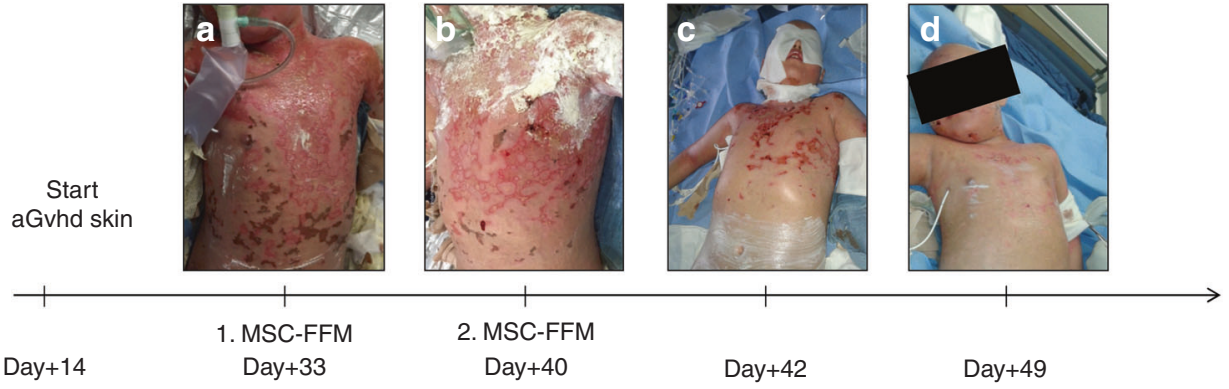

Fig. 3 Skin GvHD responds to MSC-FFM. a A representative patient with severe cutaneous aGvHD is shown at day +33 , when the first dose of MSC-FFM was given. b Improved skin at day +40 when a second dose of MSC-FFM was infused. c, d show continuously improved skin until day +49 when all involved areas completely responded cohort, only $25 \%$ of the patients exhibited aGvHD over grade III, whereas in our series, $96 \%$ of the patients exhibited aGvHD grade III or IV. Lucchini et al. [8] observed a $62.5 \%$ OR among eight patients with aGvHD (50\% grade I/II and 50\% grade III/IV). Similar findings were reported by Prasad et al. [27]. In their compassionate use study the authors could show an OR of $66.7 \%$ at day 32 in 12 pediatric patients. Kurtzberg et al. [24] achieved a
$61.3 \%$ OR rate in a large cohort of 75 pediatric patients after treatment of aGvHD with Prochymal. In contrast, we demonstrate an excellent response rate not only in children but also in adult patients. The fact that we obtained these results with a highly challenging patient cohort $(96 \%$ grade III/IV and only $4 \%$ grade II) suggests the advantage of the treatment of aGvHD with MSC-FFM. We attribute this superiority to the MSC preparation procedure. Cultivating 
Fig. 4 Intestinal GvHD responds to MSC-FFM. a, b Colonoscopy results two days before first MSC-FFM infusion. Severe GvHD with multiple ulcera and spontaneous bleeding was confirmed by histology. c, d Resolution of intestinal GvHD showed only mild proctitis two weeks after the first MSC-FFM application a

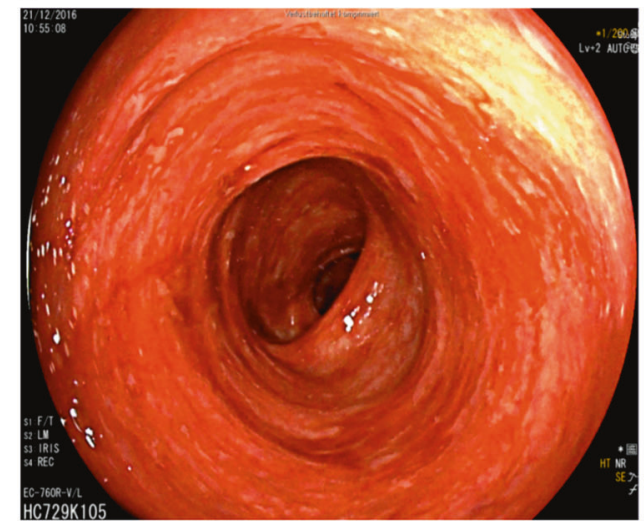

b

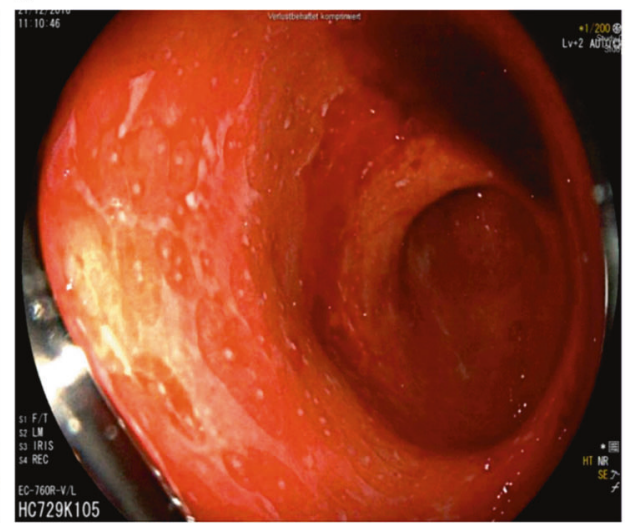

C

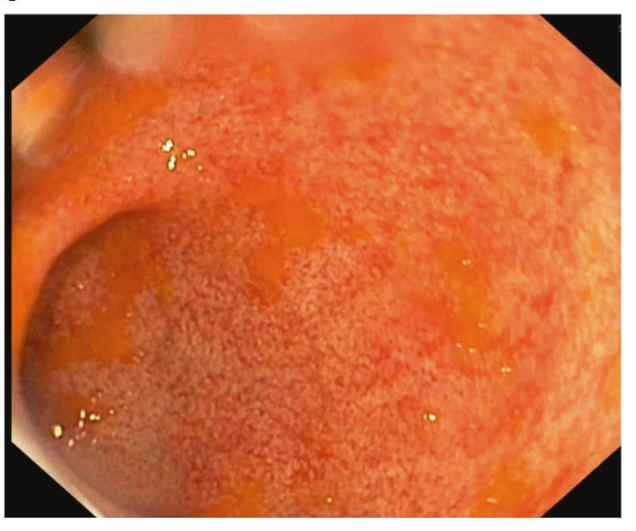

d

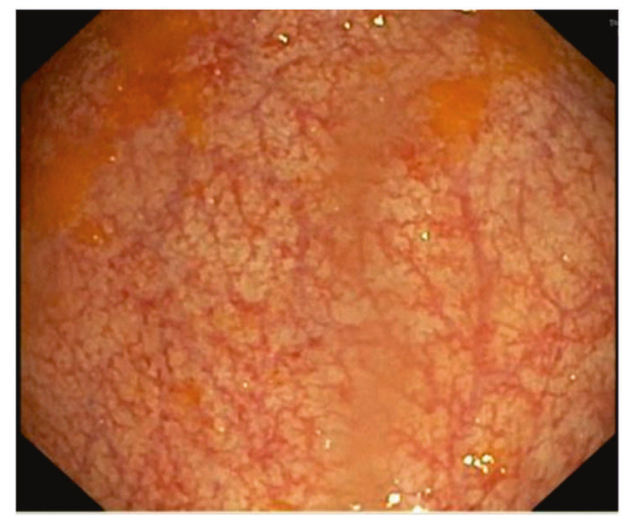

the cells out of a pool of mononuclear cells from eight different donors led to a higher in vitro suppression of a mixed lymphocyte reaction [14]. Moreover, as all therapeutic doses of the MSC-FFM product have exactly the same, standardized potential, every patient has received the same product and not as in forgoing trials different MSCs preparations from different donors. All this makes the treatment with MSC-FFM unique and distinguishes the treatment from all other reports so far.

Salmenniemi and colleagues [28] reported an OR at day 28 for adults and children of $50 \%$ and $88 \%$, respectively. The survival in the adult cohort was disappointingly low with approximately $30 \%$ at one year, while one-year survival of the MSC-treated children was $100 \%$.

Recently, Dotoli et al. [29] and von Dalowski et al. [30] reported poor outcomes in adult GvHD patients treated with MSCs after steroid-refractoriness (1-year OS: $19.6 \%$ and $19 \%$, respectively). Likewise, Salmenniemi et al. reported OS of $22 \%$ for their MSC-treated patients with GvHD after a median follow-up of 767 days (range 74-1270 days) from diagnosis [28]. Remarkably, in our cohort there was no significant difference in OS between the treated children/adolescents with MSCs
(75\% (95\% CI 64-88)) and adults (61\% (42-88)) $(P=0.398)$. While too small a cohort to derive statistically relevant information, these data are supportive for the current license of MSC-FFM for both children and adults with refractory aGvHD. In addition, the OS in children of our cohort was also better than in all previous clinical studies as reported to date [7, 24, 27]. The OR rates for steroid-refractory patients at day 28 were 100 and $80 \%$ for treatment-resistant patients (s. Table 3) at LFU. Although this difference did not achieve statistical significance $(P=0.053)$ it implies that treatment with MSC-FFM should be started as early as possible. For the time being, we recommend to start treatment with MSC-FFM as early as definitions for steroid refractivity are met [1].

Noteworthy, the six month OS of patients with grade II aGvHD $(N=3)$ was $100 \%$, with grade III $(N=25) 75 \%$ (59-94) and with grade IV $(N=41)$ was 67\% (54-84), suggesting the best survival rate reported thus far and approaching those for patients without severe GvHD (Table 4) [7, 8, 24, 26, 27, 29, 30].

In conclusion, MSC-FFM offers an excellent salvage therapy for both steroid and treatment-refractory aGvHD, warranting further clinical evaluation. 


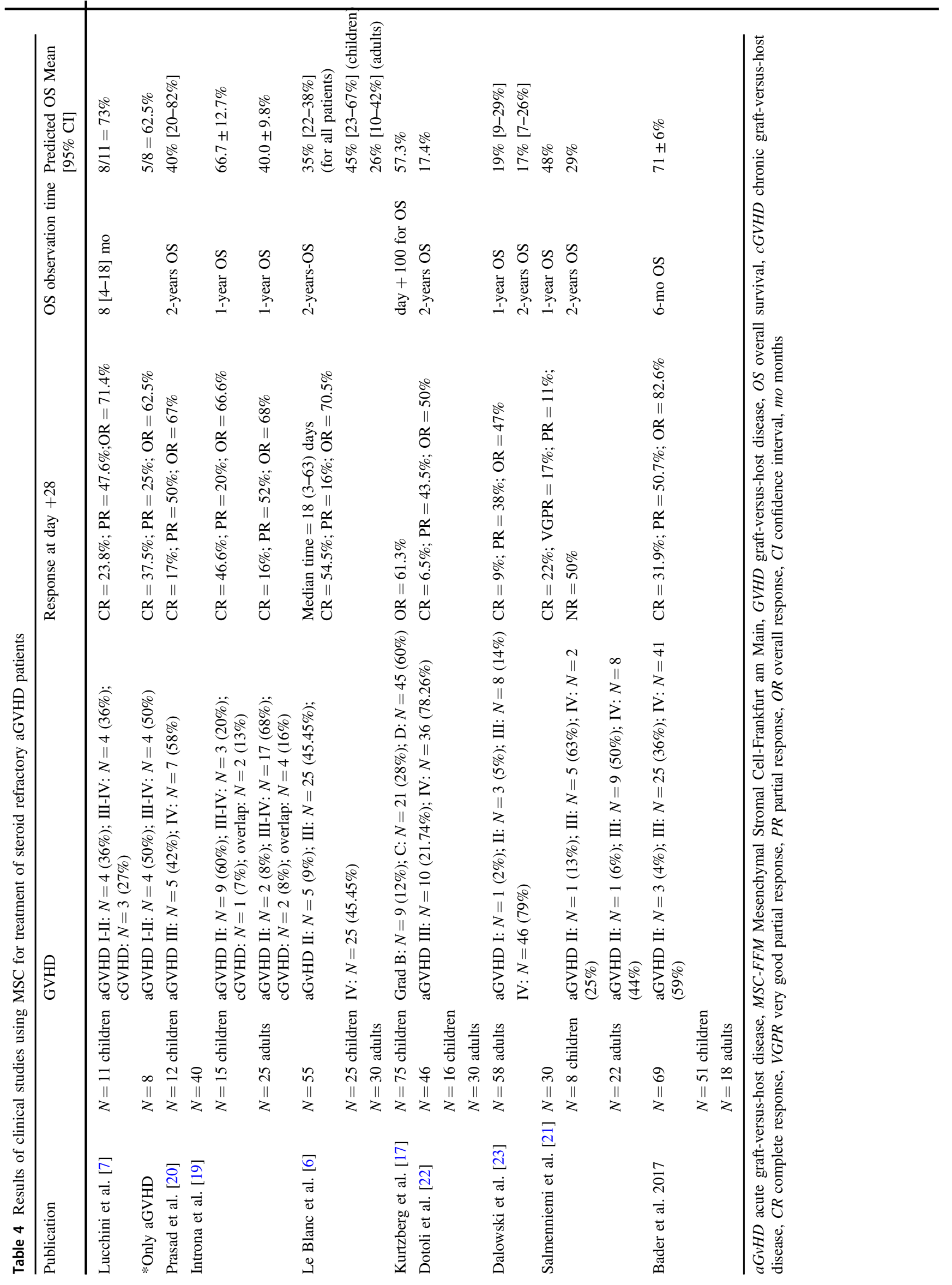


Acknowledgements The authors would like to thank following foundations for the kind support of this study: LOEWE Center for Cell and Gene Therapy Frankfurt, which is funded by the Hessian Ministry of Higher Education, Research and the Arts, (funding reference number: III L 4-518/17.004 (2013)), the "Deutsche Knochenmarkspenderdatei" (DKMS), the "Verein Hilfe für krebskranke Kinder Frankfurt e.V." and the „Frankfurter Stiftung für krebskranke Kinder".

\section{Compliance with ethical standards}

Conflict of interest PB, ZK, HB, and SK are holding IP on the MSC production. The other authors declare that they have no conflict of interest.

Open Access This article is licensed under a Creative Commons Attribution 4.0 International License, which permits use, sharing, adaptation, distribution and reproduction in any medium or format, as long as you give appropriate credit to the original author(s) and the source, provide a link to the Creative Commons license, and indicate if changes were made. The images or other third party material in this article are included in the article's Creative Commons license, unless indicated otherwise in a credit line to the material. If material is not included in the article's Creative Commons license and your intended use is not permitted by statutory regulation or exceeds the permitted use, you will need to obtain permission directly from the copyright holder. To view a copy of this license, visit http://creativecommons. org/licenses/by/4.0/.

\section{References}

1. Martin PJ, Rizzo JD, Wingard JR, Ballen K, Curtin PT, Cutler C, et al. First- and second-line systemic treatment of acute graftversus-host disease: recommendations of the American Society of Blood and Marrow Transplantation. Biol Blood Marrow Transplant. 2012;18:1150-63.

2. Deeg HJ. How I treat refractory acute GVHD. Blood. 2007;109:4119.

3. Hashmi S, Ahmed M, Murad MH, Litzow MR, Adams RH, Ball LM, et al. Survival after mesenchymal stromal cell therapy in steroid-refractory acute graft-versus-host disease: systematic review and meta-analysis. Lancet Haematol. 2016;3: e45-e52.

4. Zeiser R, Burchert A, Lengerke C, Verbeek M, Maas-Bauer K, Metzelder SK, et al. Ruxolitinib in corticosteroid-refractory graftversus-host disease after allogeneic stem cell transplantation: a multicenter survey. Leukemia. 2015;29:2062-8.

5. Le Blanc K, Rasmusson I, Sundberg B, Gotherstrom C, Hassan M, Uzunel M, et al. Treatment of severe acute graft-versus-host disease with third party haploidentical mesenchymal stem cells. Lancet. 2004;363:1439-41.

6. Ringden O, Uzunel M, Rasmusson I, Remberger M, Sundberg B, Lonnies $\mathrm{H}$, et al. Mesenchymal stem cells for treatment of therapy-resistant graft-versus-host disease. Transplantation. 2006;81:1390-7.

7. Le Blanc K, Frassoni F, Ball L, Locatelli F, Roelofs H, Lewis I, et al. Mesenchymal stem cells for treatment of steroid-resistant, severe, acute graft-versus-host disease: a phase II study. Lancet. 2008;371:1579-86.

8. Lucchini G, Introna M, Dander E, Rovelli A, Balduzzi A, Bonanomi S, et al. Platelet-lysate-expanded mesenchymal stromal cells as a salvage therapy for severe resistant graft-versus-host disease in a pediatric population. Biol Blood Marrow Transplant. 2010;16:1293-301.
9. Muller I, Kordowich S, Holzwarth C, Isensee G, Lang P, Neunhoeffer F, et al. Application of multipotent mesenchymal stromal cells in pediatric patients following allogeneic stem cell transplantation. Blood Cells Mol Dis. 2008;40:25-32.

10. Resnick IB, Barkats C, Shapira MY, Stepensky P, Bloom AI, Shimoni A, et al. Treatment of severe steroid resistant acute GVHD with mesenchymal stromal cells (MSC). Am J Blood Res. 2013;3:225-38.

11. Ball LM, Bernardo ME, Roelofs H, van Tol MJ, Contoli B, Zwaginga JJ, et al. Multiple infusions of mesenchymal stromal cells induce sustained remission in children with steroid-refractory, grade III-IV acute graft-versus-host disease. Br J Haematol. 2013;163:501-9.

12. von BL, Sundberg B, Lonnies L, Sander B, Karbach H, Hagglund $\mathrm{H}$, et al. Long-term complications, immunologic effects, and role of passage for outcome in mesenchymal stromal cell therapy. Biol Blood Marrow Transplant. 2012;18:557-64.

13. Chen X, Wang C, Yin J, Xu J, Wei J, Zhang Y. Efficacy of mesenchymal stem cell therapy for steroid-refractory acute graftversus-host disease following allogeneic hematopoietic stem cell transplantation: a systematic review and meta-analysis. PLoS ONE. 2015;10:e0136991.

14. Kuci Z, Bonig H, Kreyenberg H, Bunos M, Jauch A, Janssen JW, et al. Mesenchymal stromal cells from pooled mononuclear cells of multiple bone marrow donors as rescue therapy in pediatric severe steroid-refractory graft-versus-host disease: a multicenter survey. Haematologica. 2016;101:985-94.

15. Glucksberg H, Storb R, Fefer A, Buckner CD, Neiman PE, Clift $\mathrm{RA}$, et al. Clinical manifestations of graft-versus-host disease in human recipients of marrow from HL-A-matched sibling donors. Transplantation. 1974;18:295-304.

16. Przepiorka D, Weisdorf D, Martin P, Klingemann HG, Beatty P, Hows J, et al. 1994 Consensus Conference on Acute GVHD Grading. Bone Marrow Transplant. 1995;15:825-8.

17. Eichler H, Schrezenmeier H, Schallmoser K, Strunk D, Nystedt J, Kaartinen T, et al. Donor selection and release criteria of cellular therapy products. Vox Sang. 2013;104:67-91.

18. Prentice RL, Kalbfleisch JD, Peterson AV Jr., Flournoy N, Farewell VT, Breslow NE. The analysis of failure times in the presence of competing risks. Biometrics. 1978;34:541-54.

19. Gray RJ. A class of K-sample tests for comparing the cumulative incidence of a competing risk. The Annals of Statistics. 1988;16:1141-54.

20. Levine JE, Logan B, Wu J, Alousi AM, Ho V, Bolanos-Meade J, et al. Graft-versus-host disease treatment: predictors of survival. Biol Blood Marrow Transplant. 2010;16:1693-9.

21. Saliba RM, Couriel DR, Giralt S, Rondon G, Okoroji GJ, Rashid A, et al. Prognostic value of response after upfront therapy for acute GVHD. Bone Marrow Transplant. 2012;47:125-31.

22. Inamoto Y, Martin PJ, Storer BE, Mielcarek M, Storb RF, Carpenter PA. Response endpoints and failure-free survival after initial treatment for acute graft-versus-host disease. Haematologica. 2014;99:385-91.

23. Windrum P, Morris TC, Drake MB, Niederwieser D, Ruutu T. Variation in dimethyl sulfoxide use in stem cell transplantation: a survey of EBMT centres. Bone Marrow Transplant. 2005;36:601-3.

24. Kurtzberg J, Prockop S, Teira P, Bittencourt H, Lewis V, Chan $\mathrm{KW}$, et al. Allogeneic human mesenchymal stem cell therapy (remestemcel-L, Prochymal) as a rescue agent for severe refractory acute graft-versus-host disease in pediatric patients. Biol Blood Marrow Transplant. 2014;20:229-35.

25. Martin PJ, Uberti JP, Soiffer RJ, Klingemann H, Waller EK, Daly AS, et al. Prochymal improves response rates in patients with steroid-refractory acute graft versus host disease (SR-GVHD) 
involving the liver and gut: results of a randomized, placebocontrolled, multicenter phase III trial in GVHD. Biol Blood Marrow Transplant. 2010;16:S169-S70.

26. Introna M, Lucchini G, Dander E, Galimberti S, Rovelli A, Balduzzi A, et al. Treatment of graft versus host disease with mesenchymal stromal cells: a phase I study on 40 adult and pediatric patients. Biol Blood Marrow Transplant. 2014;20:375-81.

27. Prasad VK, Lucas KG, Kleiner GI, Talano JA, Jacobsohn D, Broadwater G, et al. Efficacy and safety of ex vivo cultured adult human mesenchymal stem cells (Prochymal) in pediatric patients with severe refractory acute graft-versus-host disease in a compassionate use study. Biol Blood Marrow Transplant. 2011;17:534-41.
28. Salmenniemi U, Itala-Remes M, Nystedt J, Putkonen M, Niittyvuopio R, Vettenranta $\mathrm{K}$, et al. Good responses but high TRM in adult patients after MSC therapy for GvHD. Bone Marrow Transplant. 2017;52:606-8.

29. Dotoli GM, De Santis GC, Orellana MD, de Lima PK, Caruso SR, Fernandes TR, et al. Mesenchymal stromal cell infusion to treat steroid-refractory acute GvHD III/IV after hematopoietic stem cell transplantation. Bone Marrow Transplant. 2017;52:859-62.

30. von Dalowski F, Kramer M, Wermke M, Wehner R, Rollig C, Alakel N, et al. Mesenchymal stromal cells for treatment of acute steroid-refractory graft versus host disease: clinical responses and long-term outcome. Stem Cells. 2016;34:357-66.

\section{Affiliations}

Peter Bader ${ }^{1}$ - Zyrafete Kuçi ${ }^{1}$ - Shahrzad Bakhtiar ${ }^{1} \cdot$ Oliver Basu $^{2} \cdot$ Gesine Bug $^{3} \cdot$ Michael Dennis $^{4}$ - Johann Greil $^{5}$. Aniko Barta ${ }^{6} \cdot{\text { Krisztián M. Kállay } \mathbb{D}^{6} \cdot \text { Peter Lang }}^{7} \cdot$ Giovanna Lucchini $^{8} \cdot$ Raj Pol $^{9} \cdot$ Ansgar Schulz $^{10}$. Karl-Walter Sykora ${ }^{11}$ - Irene von Luettichau ${ }^{12} \cdot$ Grit Herter-Sprie $^{13} \cdot$ Mohammad Ashab Uddin $^{14} \cdot$ Phil Jenkin $^{14}$. Abdulrahman Alsultan ${ }^{15} \cdot$ Jochen Buechner $^{16} \cdot$ Jerry Stein $^{17} \cdot$ Agnes Kelemen $^{18} \cdot$ Andrea Jarisch $^{1} \cdot$ Jan Soerensen ${ }^{1}$. Emilia Salzmann-Manrique ${ }^{1} \cdot$ Martin Hutter $^{1} \cdot$ Richard Schäfer $^{19} \cdot$ Erhard Seifried $^{19} \cdot$ Thomas Klingebiel $^{1}$. Halvard Bonig ${ }^{19} \cdot$ Selim Kuçi ${ }^{1}$

1 Department for Children and Adolescents, Division for Stem Cell Transplantation and Immunology, University Hospital Frankfurt, Frankfurt am Main, Germany

2 University Children's Hospital, Essen, Germany

3 Department of Medicine II, University Hospital Frankfurt, Frankfurt, Germany

4 Department of Haematology, Christie Hospital, Manchester, United Kingdom

5 University Children's Hospital Heidelberg, Heidelberg, Germany

6 Department for Haematology and SCT, St. István and St. László Hospital, Budapest, Hungary

7 University Children's Hospital Tübingen, Tübingen, Germany

8 Department of Hematology/Oncology, Great Ormond Street Hospital, London, United Kingdom

9 Department of Haematology, University of Sheffield, Sheffield, United Kingdom

10 University Children's Hospital, Ulm, Germany

11 Children's Hospital, Medizinische Hochschule, Hannover, Germany
12 Division of Pediatric Hematology/Oncology, Department of Pediatrics, Kinderklinik München Schwabing, Klinikum Rechts der Isar, Technische Universität München, München, Germany

13 Department I for Internal Medicine, University Hospital Cologne, Cologne, Germany

14 Department for Stem Cells \& Immunotherapies, NHSBT, Birmingham, Great Britain, UK

15 Department of Pediatric Hematology/Oncology, King Abdullah Specialist Children's Hospital, Riyadh, Saudi Arabia

16 Oslo University Hospital Rikshospitalet, Department of Pediatric Medicine, Section for Pediatric Hematology/Oncology, Oslo, Norway

17 Department for Hemato-Oncology, Schneider Children's Medical Center of Israel, Petach Tikva, Israel

18 B-A-Z County Hospital, Pediatric Haematology and Stem Cell Transplantation Unit, Miskolc, Hungary

19 German Red Cross Blood Center Frankfurt and Institute of Transfusion Medicine and Immunohematology, Goethe University Medical Center, Frankfurt am Main, Germany 